\title{
RESEARCH ON THE SPATIAL VARIABILITY OF SOIL MOISTURE
}

\author{
Changli Zhang ${ }^{1}$, Shuqiang Liu ${ }^{2, *}$, Xianyue Zhang ${ }^{2}$, Kezhu Tan $^{3}$ \\ ${ }^{1}$ Engineering College, Northeast Agricultural University, Harbin, Heilongjiang, China, \\ 150030; \\ ${ }^{2}$ Heilongjiang Institute of Technology, Harbin, Heilongjiang, China, 150050 \\ ${ }^{3}$ Chengdong College, Northeast Agricultural University, Harbin, Heilongjiang, China, \\ 150030; \\ * Corresponding author Address: Academic Administration,Heilongjiang Institute of \\ Technology,999 Hongqi road, Harbin, Heilongjiang,150050,P. R. China,Tel: +86-0451 \\ -88028684,+86-13946117239,Email:shuqiangliu@hotmail.com
}

\begin{abstract}
China is a country seriously suffering from the lack of water resource, especially the north of China (a dense area) where there are more agricultural production than other places in China. Therefore, some have become most important problems which should be settled down right now for precision agriculture: saving the water of agriculture, optimizing the water for cropland as well as making use of soil moisture effectively. To realise the potential of soil-moisture, protect the water source, strengthen the management of the soil moisture of farm, design the irrigation and drainage, monitor the soil-moisture, etc. ,the data collection of soil moisture and the study on how to could provide the far-reaching and academic significance of guidance together with higher regional and practical use value. The IDW, Spline and Kriging in the Spatial Analyst of ArcGIS 9.0 are applied on drawing the distributing map of soil moisture and it also offers the theoretical foundation for the connection between studying soil moisture and enhancing the yield.
\end{abstract}

Key words: Precision agriculture, Geographic information system, Spatial variability, Spatial interpolation

Please use the following format when citing this chapter:

Zhang, C., Liu, S., Zhang, X. and Tan, K., 2009, in IFIP International Federation for Information Processing, Volume 293, Computer and Computing Technologies in Agriculture II, Volume 1, eds. D. Li, Z. Chunjiang, (Boston: Springer), pp. 285-292. 


\section{INTRODUCTION}

Soil was inhomogeneous and continuous nature. Actual instance in the field indicated, in the synchronization, soil speciality also had obvious difference on the different spacial situation, this property was named the spatial variability of soil moisture (Hua et al., 1992). The most intuitionistic mode of the spatial variability of soil moisture was the spatial distribution map of soil water. Therefore, the all-important work and base of Precision Agriculture is producing the spatial distribution map of soil moisture reliably.

This study discussed the spatial variability of soil moisture, and applied Inverse Distance Weighted, Spline and Kriging interpolation of ArcGIS 9.0 to produce the spatial distribution map of soil moisture, it could offer the scientific evidence for farm management system.

\section{BASIC THEORY AND METHOD OF THE SPATIAL VARIABILITY}

\subsection{Inverse Distance Weighted Interpolation}

IDW (Inverse Distance Weighted) is a common and handy interpolation, it take an average with weight between interpolation points and modal points, its weight is more and more bigger with interpolation points.

On the assumption there are a series of discrete points, it is known the sum of coordinate points for $X_{i}, Y_{i}, Z_{i}(i=1,2, \ldots, \mathrm{n})$.

$$
Z=\left[\sum_{i=1}^{n} \frac{Z_{i}}{d_{i}^{2}}\right] /\left[\sum_{i=1}^{n} \frac{1}{d_{i}^{2}}\right]
$$

In which:

$$
d_{i}^{2}=\left(X-X_{i}\right)^{2}+\left(Y-Y_{i}\right)^{2}
$$

With the application of IDW, interpolating unit value is generated by averaging the values collected from all sampling points in nearby locations. IDW is a process which requires the evenly distribution of discrete points and their enough denseness to indicate local superficial changes in the analysis.

\subsection{Spline Interpolation}

There are two calculation methods to produce Spline function interpolation: Regularized Spline and Tension Spline. Regularized Spline produces a smooth and gradual surface and interpolation value could be 
much higher than the spectra of the values collected in sampling points. Tension Spline produces a hard surface based on characteristics of the phenomena to be formed and its interpolation result are more fitted within the spectra of values collected in sampling points.

A general formula of Spline interpolation is:

$$
Z_{0}=\frac{\sum_{i=1}^{s} Z_{i} \frac{1}{d_{i}^{K}}}{\sum_{i=1}^{s} \frac{1}{d_{i}^{K}}}
$$

In this formula, $Z_{0}$ is the estimated value of Point $0 ; Z_{i}$ is $\mathrm{Z}$ value of Control Point $\mathrm{i} ; d_{i}$ is the distance between Control Point $i$ and Point $0 ; s$ is the number of Control Point in estimating; $k$ is a designated power.

\subsection{Kriging Interpolation}

Kriging Interpolation is the most common interpolation method in geostatistics(Webstre R.. et al., 1985; Trangmar B B. et al., 1985) It is the method of optimized and precise estimation of partial variables in unobserved locations with application of original data and configuration of semi-variance function(Wollenhaupt N C et al., 1997). It doe not only consider the distance but also apply the variance function and configuration analysis to consider the relation between the spatial distribution of known sampling points and the spatial location of unknown sampling points. Kriging method produces the value for unknown sampling points with values for known points. This is shown:

$$
Z\left(x_{0}\right)=\sum_{i=1}^{n} \lambda_{i} Z\left(x_{i}\right)
$$

$\mathrm{Z}(\mathrm{x} 0)$ was the value of unknown points, $\mathrm{Z}(\mathrm{xi})$ was known swatch points around unknown points, $\lambda_{i}$ was the power that point $i$ to unknown points. For satisfying non-Biased and optimality, passed establishing Kriging formula to ascertain weight coefficient(Li et al., 2006) :

$$
\left\{\begin{array}{l}
\sum_{j=1}^{n} \lambda_{j} \gamma\left(x_{i}, x_{j}\right)+\mu=\gamma\left(x_{i}, X\right) \\
\sum_{i=1}^{n} \lambda_{i}=1
\end{array}\right.
$$

$\gamma\left(x_{i}, x_{j}\right)$ is covariance function in sampling points, $\gamma\left(x_{i}, X\right)$ was covariance function between sampling points and interpolation points, $\mu$ was Lagrange multiplier. 


\section{DESIGN OF THE EXPERIMENT}

Experiment farmland was a soybean field of Heilongjiang Daxijiang farm, its area was about $9.8 \mathrm{hm}^{2}$. June 27, 2006, soil moisture was measured with the help of GPS and measuring instrument of soil moisture, grid was setting by $15 \mathrm{~m} \times 15 \mathrm{~m}$, about 250 points, sampling deepness was $10 \mathrm{~cm}$. 9800 Uranus dual-frequency RTK of the South Mapping Co. was used to measure the evaluation data of this land.

Sampling mode of soil moisture was point sampling(Joseph K. Berry et al., 1999; Wollenhaupt N C et al., 1997; Hao et al., 2002), inerratic grid sampling disjoins the farmland to equal area grid. It is simple and exercisable, is the most effective one of sampling method and is much more precise than random sampling mode. Besides pane shape, triangle grid, rectangle or hexagon are able to be used. Inerratic grid sampling distribution is shown in figure. This research considered sampling convenience and actual condition, compartmentalized grid along ridge in a field generally.

This research on spatial variance of farmland moisture started with sampling soil. The instruments for sampling soil include GPS and measuring instrument of soil moisture. Mostly, the sampling deepness equals the tilth deepness. In this research, the sampling deepness is $10 \mathrm{~cm}$.

\section{EVALUATION DATA ANALYSIS}

Evaluation Map is produced with the use of 9800 Uranus dual-frequency RTK of the South Mapping Co. to measure the evaluation data of this land, the set-up of network $15 \mathrm{~m} \times 15 \mathrm{~m}$, the application of Kriging Interpolation of Spatial Analyst model in geographical information software ArcGIS 9.0.

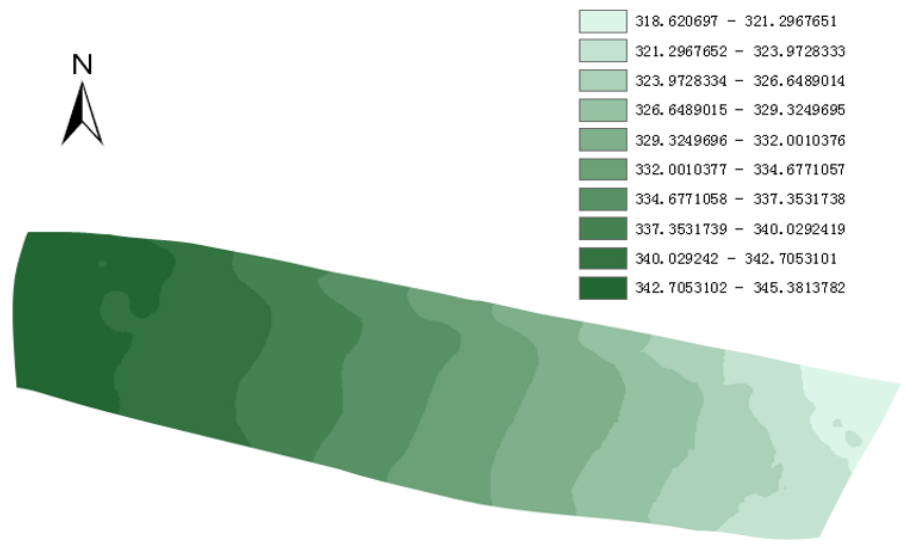

Fig. 1 Elevation map of the experimental field 


\section{ANALYSIS ON THE SOIL MOISTURE DATA}

\subsection{Calculating the statistical eigenvalue of soil moisture speciality}

In accordance with the classic statistical method, we calculated the statistical eigenvalue of evaluation data of soil moisture in the experiment land and its results are listed in Table 1 . The average value of the measured soil moisture is $27.5 \%$. The variance coefficients of these three moisture measurements are $119.2 \%, 117.3 \%, 127.6 \%$. The classification of variance coefficient includes weak variability, $\mathrm{CV}<10$; medieval variability $\mathrm{CV}=$ $10 \sim 100$; strong variability $\mathrm{CV}>100$. The data indicate that soil moisture of this land attributes to Strong Variability.

Table 1 Statistical description of soil moisture

\begin{tabular}{ccccccc}
\hline Date & $\begin{array}{c}\text { Minimu } \\
\mathrm{m} \\
\text { value }\end{array}$ & $\begin{array}{c}\text { Maximal } \\
\text { value }\end{array}$ & $\begin{array}{c}\text { Average } \\
\text { value }\end{array}$ & $\begin{array}{c}\text { Standard } \\
\text { value }\end{array}$ & Variance & $\begin{array}{c}\text { Variance } \\
\text { coefficien } \\
\mathrm{t}\end{array}$ \\
\hline August 8,2006 & 0.099 & 0.45 & 0.275 & 0.351 & 0.123 & 127.6 \\
\hline
\end{tabular}

\subsection{Testing normal distribution of soil moisture data}

Testing normal distribution of soil moisture data was the precondition of using interpolation to analyze soil moisture feature data, because only the data distribution is normal, should interpolation be valid. Normal QQ plot is a statistical figure for testing normal data distribution. Given the sampling data is distributed normally, the sampling points should be a line in its normal QQ distribution plot. Besides, given the data is not shown in normal distribution, there will be a necessity to converse the data before the application of interpolation in order to be distributed normally.

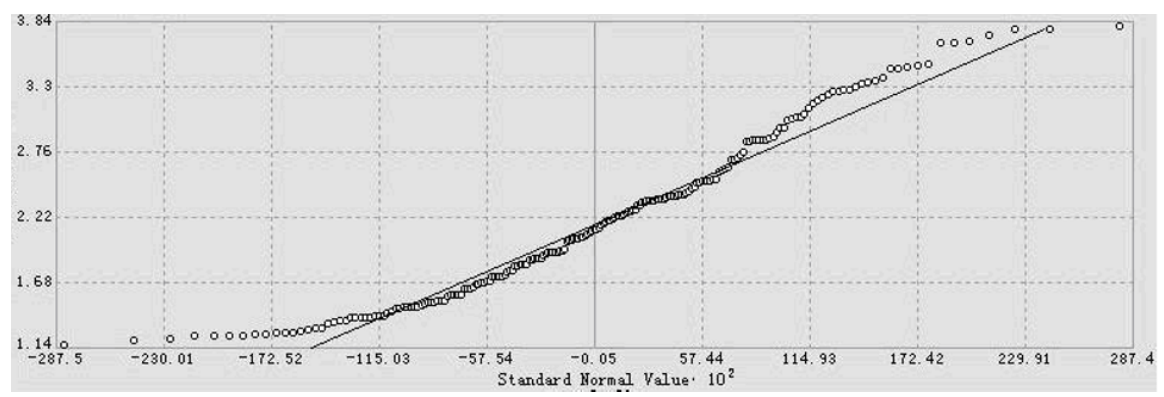

Fig.2 Normal QQ plots of soil moisture properties 
The normal distribution of soil moisture feature was tested In ArcGIS, see Table 1. Results showed that most sampling points were distributed normally and the few sampling points departed far away from the straight line. After testing, all these data are eligible and can be interpolated.

\subsection{Analyzing the spatial interpolation of soil moisture speciality}

For describing true and intuitionistic spatial distribution of soil moisture, the research used Spatial Analyst module in ArcGIS 9.0, applied IDW、 Spline、Kriging Interpolation to obtain the distributing map of soil moisture.

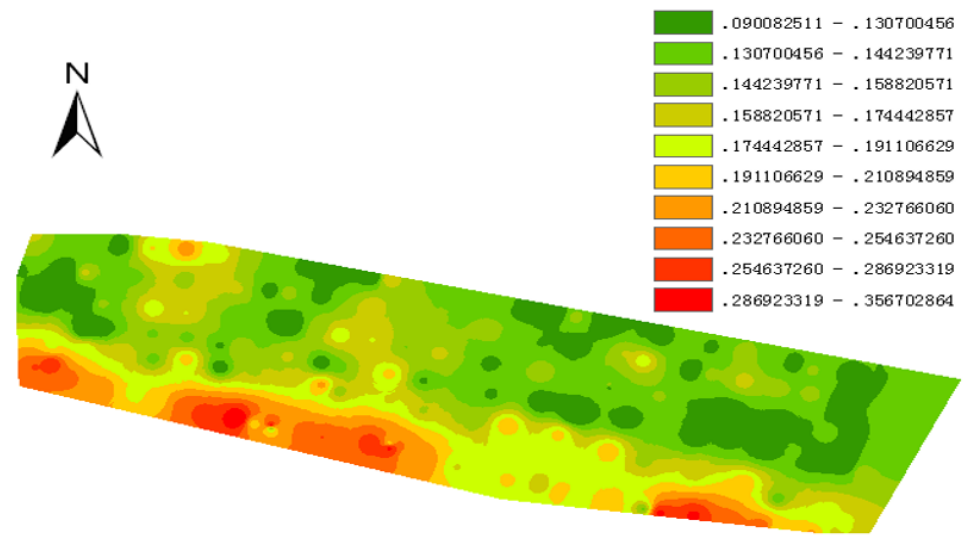

Fig.3 Map of soil moisture interpolated by IDW

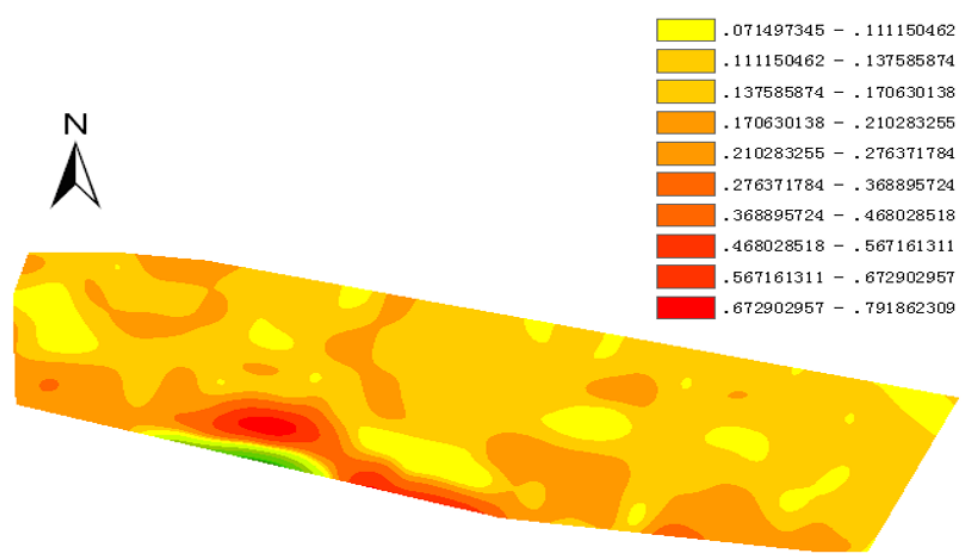

Fig. 4 Map of soil moisture interpolated by Spline 


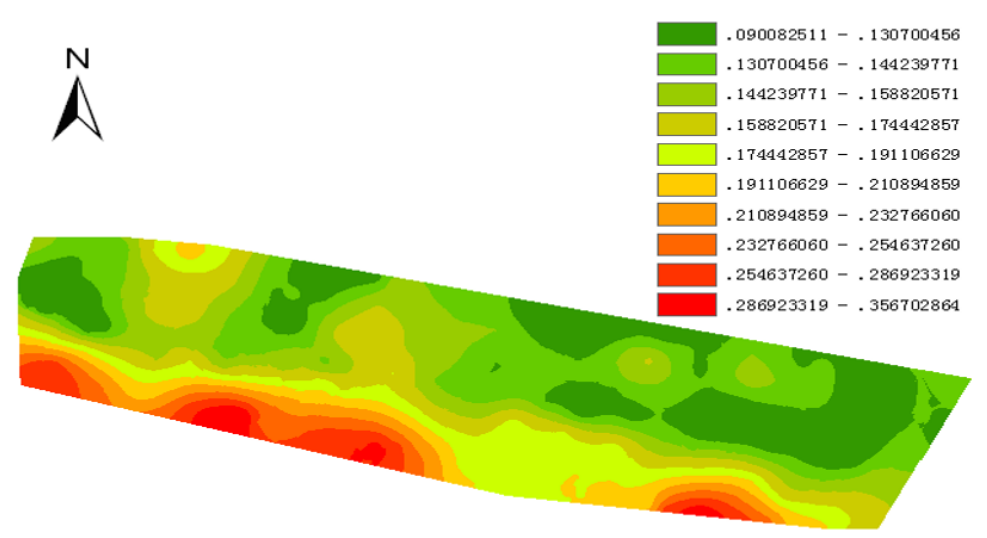

Fig. 5 Map of soil moisture interpolated by Kriging

\section{CONCLUSION}

1) All of the soil spatial property is normal distribution and the spatial distribution of soil water property accord with the actual.

2) The three soil moisture graphs shows that soil moisture speciality distribution maps with the application of the three interpolation methods all effectively reflect the actual spatial distribution of soil moisture. The distribution of relatively high-value areas of soil moisture is almost consistent with that of relatively low-value areas, although there are differences in the spatial distribution maps of soil moisture because of the different mathematical principles applied.

3 ) with the application of IDW and Spline Interpolation methods, the soil moisture spatial distribution maps are characterized as spot-shape, discrete, and ,however, retaining the singular value (the specific maximum or minimum in local areas) of original estimate value, forming gradual island distribution around the center of the singular point. Kriging method, based on the trend of spatial changes of soil moisture property, could make proper modifications on singular value to avoid the impact of spatial distribution of variance on partial singular values.

4) Kriging method considers the randomicity of the soil property as well as the structure of the soil property. It is the most appropriate mathematical method for the research on spatial variability of soil moisture. The spatial distribution map of soil moisture by Kriging interpolation is better to help researchers precisely and well understand the spatial distribution of the whole cropland soil moisture. Making a veracious spatial distribution map of soil moisture is of significance in promptly adjusting precise agriculture 
management like fertilization and irrigation. It also offers the theoretical foundation for studying the connection between soil moisture and the yield.

5) When using spatial interpolation methods, it should choose the best method to get the most perfect effect of the spatial interpolation, the precondition is comparing the experimentations with the different actual instance of the experimental cropland and analyzing the actual metrical data of the sampling points adequately. The most importance was improving on interpolation methods, putting forward a new better scientific interpolation based on existing foundation.

\section{REFERENCES}

Hao P.F., Liu G., Jiang W.K. 2002. Approaches to processing soil fertility spatial distribution information for precision agriculture. Journal of Agricultural University of Hebei.25: 277278.

Hua M., Wang J. 1992. Soil Physics. BeiJing :BeiJing agriculture publishing company.

Joseph K. Berry. The Precision Farming Primer.BASIS,Inc.1999.

Li J., You S.C., Huang J.F. 2006. Spatial interpolation method and spatial distribution characteristics of monthly mean temperature in China during 1961-2000. Ecology and Environment.15(1):109-114.

Trangmar B B. Yost R S. Uehara G. Application of geo-statistica to spatial studies of soil properties[J].Advanced Agronomy.1985 38:44-94

Webstre R.Quantitative spatial analysis of soil in the field[J].Advance in soil science, 1985,(3):2-66.

Wollenhaupt N C, Mulia D J, Gotway Crowford C A. 1997. Soil Sampling and Interpolation Techniques for Mapping Spatial Variability of Soil Properties .The Site-Specific Management for Agricultural Systems. ASA-CSSA-SSSA, 777 S.Segoe Rd.,Madison, WI53711,USA. 19-53.

Wollenhaupt N C, Mulia D J, Gotway Crowford C A. 1997. Soil Sampling and Interpolation Techniques for Mapping Spatial Variability of Soil Properties .The Site-Specific Management for Agricultural Systems. ASA-CSSA-SSSA, 777 S.Segoe Rd.,Madison, WI53711,USA. 19-53. 